\title{
High resolution magnetic resonance imaging in peripheral vestibular dysfunction in multiple sclerosis
}
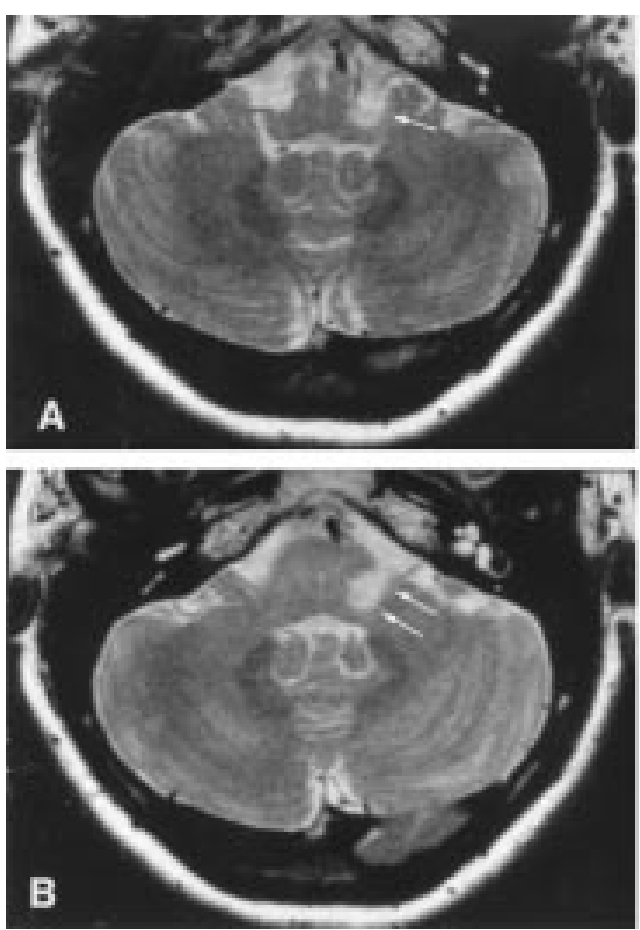

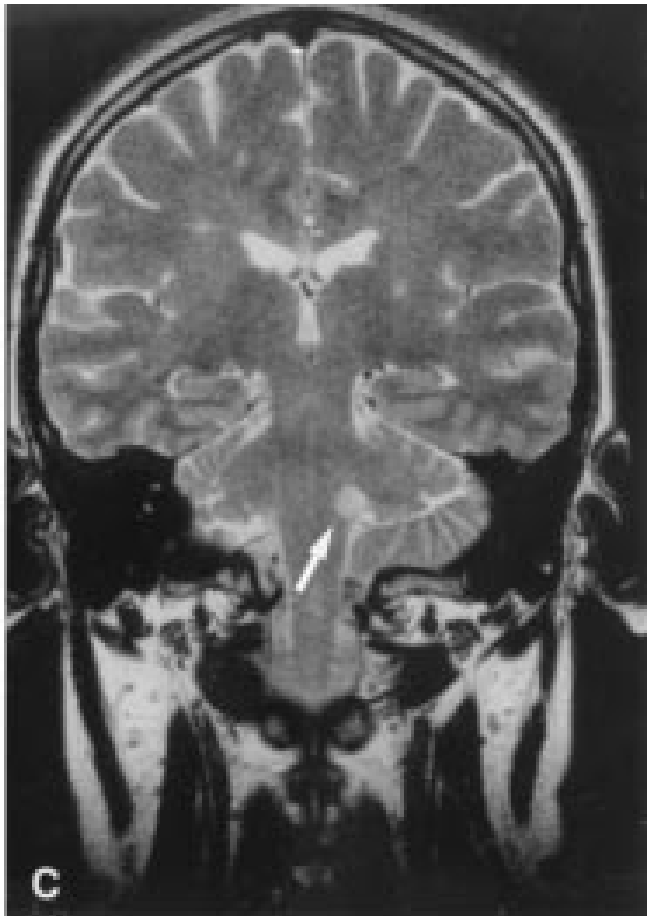

High resolution T2 weighted axial $(A, B)$ and coronal $(C)$ Turbo Spin Echo MRI (TR/TEef 2730/105, ETL 7, NEX 6, matrix $364 \times 512$, voxel size of $2 \times 0.41 \times 0.57 \mathrm{~mm})$. A hyperintense lesion at the pontomedullary junction on the left involving the entry zone of eighth nerve fibres with sparing of the vestibular nuclei is shown (arrows).
A 28 year old woman with a 2 year history of relapsing-remitting multiple sclerosis presented with sudden onset severe vertigo, falling to the left, and spontaneous nystagmus with a rotatory component to the right side. Electronystagmography with caloric testing showed a right preponderance with a reduced stimulus response on the left side indicating an incomplete lesion of the horizontal semicircular canal. Slight abnormalities were seen on audiometry (slight deficit on the left) and auditory evoked potentials (isolated increase of the interpeak latency between waves III and IV on the left $(1.0 \mathrm{~ms}$ on the right, $1.7 \mathrm{~ms}$ on the left)). T2 weighted MRI showed four small supratentorial and a single infratentorial lesion (figure). There was slight peripheral contrast enhancement on T1 weighted MRI. On high dose intravenous steroids symptoms improved significantly within a week with full recovery at follow up after 3 months. The site of the lesion in this patient is in line with experimental studies of caloric responses after various focal lesions in and around the vestibular nuclear complex in monkeys when vestibular paresis occurred only with lesions involving the eighth nerve root entry zone. ${ }^{1}$

$$
\begin{array}{r}
\text { A GASS } \\
\text { W STEINKE } \\
\text { A SCHWARTZ } \\
\text { M G HENNERICI } \\
\text { Department of Neurology, Klinikum Mannheim, } \\
\text { University of Heidelberg, Germany }
\end{array}
$$

Correspondence to: Dr A Gass, Department of Neurology, Klinikum Mannheim, Theodor Kutzer Ufer, 68137 Mannheim, FR Germany. Telephone 0049621383 2885; fax 00496213833807 .

\footnotetext{
1 Uemura T, Cohen B. Effects of vestibular nuclei lesions on vestibulo-ocular reflexes and posture in monkeys. Acta Otolaryngol Suppl Stockh 1973;315:1-71.
} 